Published in final edited form as:

J Cardiovasc Nurs. 2019 ; 34(2): 183-192. doi:10.1097/JCN.0000000000000543.

\title{
Psychometric Testing of the Revised Self-Care of Heart Failure Index
}

\author{
Barbara Riegel, PhD, RN, FAAN [Edith Clemmer Steinbright Professor of Gerontology], \\ School of Nursing, University of Pennsylvania, Philadelphia. \\ Claudio Barbaranelli, PhD [Professor of Psychometry], \\ Sapienza University of Rome, Italy.
}

Beverly Carlson, PhD, RN, FAHA [Assistant Professor], School of Nursing, San Diego State University, California.

Kristen A. Sethares, PhD, RN, CNE, FAHA [Professor],

School of Nursing, University of Massachusetts Dartmouth.

Marguerite Daus, BSN, RN [Doctoral Student],

University of Pennsylvania School of Nursing, Philadelphia.

Debra K. Moser, PhD, RN, FAAN [Professor and Linda C. Gill Chair of Cardiovascular Nursing],

College of Nursing, University of Kentucky, Lexington.

Jennifer Miller, PhD, RN [Assistant Professor],

College of Nursing, University of Kentucky, Lexington.

Onome Osokpo, MSN, RN [Ruth L. Kirschstein NRSA Doctoral Fellow],

Research on Vulnerable Women, Children and Families (T32NR007100), University of

Pennsylvania School of Nursing, Philadelphia.

Solim Lee, MSN, RN [PhD Candidate],

University of Pennsylvania School of Nursing, Philadelphia.

Stacey Brown, MA [Project Manager],

University of Pennsylvania School of Nursing, Philadelphia.

Ercole Vellone, PhD, RN, FESC [Assistant Professor]

University of Rome Tor Vergata, Italy.

\section{Abstract}

Background: Self-care is essential in people with chronic heart failure (HF). The process of selfcare was refined in the revised situation specific theory of HF self-care, so we updated the instrument measuring self-care to match the updated theory. The aim of this study was to test the psychometric properties of the revised 29-item Self-Care of Heart Failure Index (SCHFI).

Correspondence: Barbara Riegel, PhD, RN, FAAN, University of Pennsylvania School of Nursing, 418 Curie Blvd, Philadelphia, PA 19104-4217 (briegel@nursing.upenn.edu).

Barbara Riegel was funded through R01 NR018196. Marguerite Daus was funded through T32 NR007104 
Methods: A cross-sectional design was used in the primary psychometric analysis using data collected at 5 sites in the United States. A longitudinal design was used at the site collecting testretest data. We tested SCHFI validity with confirmatory factor analysis and predictive validity in relation to health-related quality of life. We tested SCHFI reliability with Cronbach a, global reliability index, and test-retest reliability.

Results: Participants included 631 adults with HF (mean age, $65 \pm 14.3$ years; $63 \%$ male). A series of confirmatory factor analyses supported the factorial structure of the SCHFI with 3 scales: Self-Care Maintenance (with consulting behavior and dietary behavior dimensions), Symptom Perception (with monitoring behavior and symptom recognition dimensions), and Self-Care Management (with recommended behavior and problem-solving behavior dimensions). Reliability estimates were 0.70 or greater for all scales. Predictive validity was supportive with significant correlations between SCHFI scores and health-related quality-of-life scores.

Conclusions: Our analysis supports validity and reliability of the SCHFI v7.2. It is freely available to users on the website: www.self-care-measures.com.

\section{Keywords}

heart failure; psychometrics; reliability; self-care; validity

Self-care is integral in maintaining the physical and emotional stability of chronically ill individuals. ${ }^{1}$ In chronic heart failure (HF), self-care is particularly important because the treatment regimen is complex. These patients typically take an average of 10 medications daily. ${ }^{2}$ They are advised to limit dietary sodium, stay physically active, monitor signs and symptoms, and actively engage in symptom management when changes are observed. ${ }^{3}$

Given the intricacies of self-care and the importance of self-care to clinical stability, it is essential to have an instrument to measure self-care.

We developed an instrument to measure HF self-care, ${ }^{4}$ which was updated most recently in 2009. ${ }^{5}$ The instrument was based on our theoretical work, the situation specific theory of HF self-care, which was originally published in $2008 .{ }^{6}$ In 2016 , we updated this theory to address the important observation that symptom perception is an essential element of the HF self-care process. ${ }^{7}$ Now, we have updated the Self-Care of Heart Failure Index (SCHFI) to match the updated theory. In this article, we describe the psychometric properties of the revised SCHFI 7.2.

The SCHFI has been used frequently since it was originally published. A PubMed search in August 2018 revealed 74 articles citing the SCHFI. Another search in Google Scholar, which included unpublished materials (eg, master and $\mathrm{PhD}$ theses), revealed 911 documents citing the SCHFI. What we have learned from these studies is that a wide variety of factors predict self-care behaviors: experience, ${ }^{8}$ skill,${ }^{9}$ values,${ }^{10}$ cognitive and functional abilities, ${ }^{11}$ depression, ${ }^{12}$ confidence or self-efficacy, ${ }^{13-16}$ social support, ${ }^{13,17-20}$ and access to healthcare. ${ }^{21}$ We have also learned that HF self-care can improve outcomes, including quality of life. ${ }^{22-26}$ The SCHFI v6.2 has been translated into 21 international languages. Translations are freely available on the website (www.self-care-measures.com), attesting to the international relevance of the instrument. ${ }^{24,25}$ 
The original version of the SCHFI v.4 was 15 items in length, rated on a 4-point response scale, and divided into 3 scales measuring self-care maintenance, self-care management, and self-care confidence. ${ }^{4}$ Although confidence is not a self-care behavior, we included it because it is an important predictor of self-care. We tested this version in a sample of 760 patients with HF enrolled from 7 US sites. At that point, we were adding the scores to obtain a summary score. Reliability of the summary score, tested by Cronbach $a$, was adequate (0.76), but reliability of the Self-Care Maintenance scale was only 0.56 . Reliability of the Self-Care Management scale was 0.70, whereas the reliability of the Self-Confidence scale was 0.82 . Construct validity was supported. We updated the instrument in 2009 (v.6.2) by adding items to the Self-Care Maintenance scale and refining the response format. We modified the SCHFI scoring procedure, advocating that the scale scores be used separately (not added). ${ }^{5}$ Unfortunately, the addition of items did not significantly change the Self-Care Maintenance scale coefficient $a$. At that point, we advocated a score of 70 or greater as a cut point to judge self-care adequacy. This cut point was chosen on a pragmatic basis but later found to be associated with the best 1 -year event-free survival. ${ }^{27}$

Further evidence of reliability and validity was published over the years. Construct validity, contrasting groups' validity, internal consistency, and test-retest reliability were demonstrated in a large sample of 659 patients with HF from Italy. ${ }^{28}$ Noting that Cronbach a coefficient assumes a unidimensional scale, Barbaranelli et al ${ }^{29}$ tested dimensionality and internal consistency reliability of the SCHFI in a sample of 629 adults with HF enrolled in the United States. Dimensionality was tested using confirmatory factor analysis (CFA); reliability was tested using coefficient $a$ and alternative options. The Self-Care Maintenance and Self-Care Management scales were found to be multidimensional, meaning that more than 1 latent variable explains correlations among observed variables in the data set. Because Cronbach $a$ is not the best estimate of reliability for multidimensional scales, new and more appropriate reliability estimates such as the global reliability index for multidimensional scales were used. ${ }^{30}$ When reliability was estimated with these methods, reliability was adequate or high.

\section{Revised Situation-Specific Theory of Heart Failure Self-Care}

In 2012, we published the middle-range theory of self-care of chronic illness, ${ }^{1}$ in which we proposed the concept of self-care monitoring, which includes the processes of symptom detection, interpretation, and response. In 2013, we demonstrated a linear self-care process in which self-care maintenance was associated with symptom monitoring, which was then associated with treatment implementation and evaluation. ${ }^{31}$ Together, these findings raised our awareness that the process of symptom monitoring was not sufficiently addressed in the situation-specific theory of HF self-care. ${ }^{6}$ Thus, we revised the theory to incorporate symptom monitoring. The addition of content on symptom monitoring was the major addition to this instrument revision. Because HF causes neurological lesions that can interfere with the ability of patients to detect and interpret changes in signs and symptoms, 32,33 we named the concept symptom perception in the situation-specific theory. ${ }^{7}$ Symptom perception was said to involve monitoring, body listening, symptom recognition and interpretation, and labeling of signs and symptoms. 


\section{Methods}

The aim of this study was to test the psychometric properties of the revised SCHFI after it was revised to match the updated situation specific theory of HF self-care. ${ }^{7}$ A crosssectional design was used in the primary psychometric analysis. A longitudinal design was used at the site collecting test-retest data.

\section{Sampling}

Data for this analysis were obtained from 5 US sites representing the northeast, the southeast, and the southwest. After local institutional review board approval at all sites, stable patients were recruited from both inpatient and outpatient sites. All participants were older than 18 years, were able to read and write in English, and had been diagnosed with chronic HF according to the American Heart Association guidelines. ${ }^{3}$ No specific type of HF was targeted for enrollment because all patients with HF need to perform self-care. Patients with a diagnosis of dementia or listed for heart transplantation were excluded. All participants provided informed consent to participate. At the site where longitudinal followup survey data were collected, patients were excluded if they did not have a telephone or a mailing address.

In the hospital, potential subjects were identified from automated hospital records or by referral from clinicians at the hospital. In outpatient sites, patients were recruited from outpatient cardiology clinics and cardiac rehabilitation settings. After potential participants were identified and agreed to meet with a research team member, they were approached and invited to join the study. Those who met the inclusion criteria and chose to participate completed a survey packet including a sociodemographic questionnaire and the SCHFI. Clinical information about HF and comorbid conditions were collected at each site.

\section{Instrument}

The revised SCHFI (v7.2) consists of 29 items divided into 3 scales measuring self-care maintenance, symptom perception, and self-care management. The Self-Care Confidence scale is not reported here because it is not part of self-care per se. That is, self-care confidence is a powerful influence on self-care, and we always collect data on self-care confidence with the scale on the website, but it is not a self-care behavior.

Each SCHFI scale uses Likert-type response options. The Self-Care Maintenance scale includes 10 behaviors measured in terms of frequency (1, never, to 5, always). The Symptom Perception scale includes 9 items assessing frequency of behaviors and 2 items on how quickly symptoms were recognized and identified as HF related. Response options for the 2 recognition items range from "not applicable" (no symptoms) or 0 (did not recognize symptom) to 5 (very quickly). The Self-Care Management scale includes 8 items. Seven of these items ask how likely the respondent would be to try behaviors commonly used to control HF symptoms (1, not likely, to 5, very likely). One Self-Care Management question asks how sure the patient is that the treatment last used to manage symptoms helped with feeling better. Response options for this item range from 0 (I did not do anything) or 1 (not sure) to 5 (very sure). 
Each scale (Self-Care Maintenance, Symptom Perception, and Self-Care Management) is scored separately. Response choices for all items in the scale are summed and standardized to achieve a possible score of 0 to 100 , with higher scores indicating better self-care. On the basis of the earlier version of the SCHFI v6.2, we believe that a score of 70 or better can be used to identify an adequate level of HF self-care. One half standard deviation, or an 8-point difference in the standardized score, was recommended as a minimal clinically relevant change in scores for the previous version, and we see no need to change this recommendation at this point. ${ }^{34}$

\section{Analysis}

Testing of dimensionality precedes reliability testing, ${ }^{30}$ so we began with factor analysis and then assessed reliability. Because the instrument is theory based, we also tested a general model, where all items and all 3 scales were analyzed with CFA to confirm the factorial validity of the 3 separate scales. We conducted the CFA in Mplus 8.1. ${ }^{35}$ Factor loadings greater than $|0.30|$ were considered adequate. ${ }^{36,37}$ Because several items had nonnegligible positive kurtosis, we used the robust maximum likelihood method for parameter estimation. Several goodness-of-fit indices were used to examine model fit: the comparative fit index (CFI), the Tucker-Lewis Index (TLI), the root mean square error of approximation (RMSEA), and the standardized root mean square residual (SRMR). ${ }^{38-40}$ The CFI and TLI were used to compare the model of interest with a null model. ${ }^{41}$ Values of 0.90 to 0.95 indicate acceptable fit, and values greater than 0.95 indicate good model fit. ${ }^{42}$ Root mean square error of approximation was used to estimate lack of model fit, with values of 0.05 or less indicating a well-fitting model, 0.05 to 0.08 indicating a moderate fit, and 0.10 or greater indicating poor fit. ${ }^{43}$ Standardized root mean square residual was used as a measure of fit in the sample, with values of 0.08 or less indicating good fit. Traditional $\chi^{2}$ statistics are reported but were not used in interpreting model fit because the $\chi^{2}$ likelihood ratio test is sensitive to sample size.

Using SPSS v.25 (IBM, Armonk, New York), we randomly split the sample into 2 subsamples. For each one of the 3 scales of the SCHFI, we conducted CFAs where 1 subsample was used to develop the model (eg, eliminating items with inadequate loadings) and the second subsample was used to validate the trimmed solution obtained from the first subsample. ${ }^{44,45}$ The final replicated trimmed model was rerun on the total sample to obtain parameter estimates that were more stable in dimensionality and reliability. The total sample also was used to conduct a simultaneous CFA in which we tested the whole model with all the 3 scales, their dimensions, and the items belonging to each dimension. This analysis was conducted to provide further evidence of the dimensionality of the revised situation-specific theory of HF self-care.

Scale reliability was estimated with Cronbach a coefficients, as well as with composite reliability ${ }^{46}$ or the omega coefficient, ${ }^{47}$ where values of 0.7 or greater are considered adequate. ${ }^{48}$ Item discrimination was estimated with item-total corrected correlation coefficients, ${ }^{49}$ where values of 0.3 or greater are considered adequate. ${ }^{50}$ Test-retest reliability was computed on a subsample of 50 subjects from 1 site. In these participants, the SCHFI was read-ministered 2 weeks after the first administration. 
Predictive validity was tested using data on health-related quality of life (HRQL) collected using the Short-Form (SF)-36 v2 (used with permission from QualityMetric, Inc). The SF-36 has been demonstrated repeatedly to be a reliable and valid measure. ${ }^{51}$ Higher scores reflected poorer HRQL. Data on HRQL were collected on a sample of 89 participants from a single site. Participants were asked to report their HRQL over the 4 weeks before hospitalization. We hypothesized that individuals practicing better self-care would report better general health, fewer role limitations, better mental health, and better physical health on the SF-36. Data were analyzed with Pearson correlation coefficient. This analysis was performed in a small subsample, so any $P$ value less than .10 was considered statistically significant in this analysis.

\section{Results}

The sample of 631 adults was predominately male, white, non-Hispanic, and married, with a mean age 65 years (range, 20-104 years) (Table 1). Most had at least some college education and were unemployed or retired. On average, participants had HF for more than 10 years. Half of this sample had moderate to high comorbidity burden, measured at most sites by the Charlson Comorbidity Index. ${ }^{52}$ The most common comorbid conditions were hypertension, diabetes, and arthritis.

\section{Self-Care Maintenance Scale}

Dimensionality.-Authors of previous psychometric studies ${ }^{22,53}$ have shown that the selfcare maintenance behaviors comprise 2 dimensions: consulting behaviors and dietary behaviors. Consequently, we expected the 11 items of the Self-Care Maintenance scale to reflect these 2 dimensions. In the consulting behavior dimension, we put the following items: try to avoid getting sick, get some exercise, see your healthcare provider for routine healthcare, take prescribed medicines without missing a dose, make sure to get a flu shot annually, avoid cigarettes and tobacco smoke, ask your healthcare provider about your medicines, and use a system or method to help you remember to take your medicines. In the dietary behavior dimension, we put the following items: eat a low-salt diet, order low-salt items when eating out, and ask for low-salt foods when visiting family and friends. Thus, we first specified a 2-factor confirmatory model. One item (avoid cigarettes and tobacco smoke) fit poorly and was eliminated from further analyses but retained in the scale for further testing. Without this item, the goodness of fit indices of the model with 10 items were good: $\chi^{2}(33, \mathrm{~N}=316)=65.06, P<.001, \mathrm{CFI}=0.93, \mathrm{TLI}=0.90, \mathrm{RMSEA}=0.055(90 \%$ confidence interval $[\mathrm{CI}], 0.035-0.075), P=.30, \mathrm{SRMR}=0.048$. Because the item on using a method to help remember medicines presented nonsignificant loadings, the model was respecified fixing this loading at zero. When the CFA was rerun, the model had an adequate fit to the data: $\chi^{2}(34, \mathrm{~N}=316)=65.38, P<.001, \mathrm{CFI}=0.93, \mathrm{TLI}=0.90, \mathrm{RMSEA}=0.054$ (90\% CI, 0.034-0.074), $P=.35$, SRMR $=0.048$. This final trimmed model was perfectly replicated on the second validation subsample: $\chi^{2}(43, \mathrm{~N}=315)=39.74, P=.23, \mathrm{CFI}=$ $0.99, \mathrm{TLI}=0.98, \mathrm{RMSEA}=0.023(90 \% \mathrm{CI}, 0.00-0.049), P=.96, \mathrm{SRMR}=0.037$.

When we merged the 2 subsamples and reran the CFA on the full sample of 631 subjects, the model had excellent fit indices: $\chi^{2}(34, \mathrm{~N}=631)=70.95, P<.001, \mathrm{CFI}=0.96, \mathrm{TLI}=0.94$, 
RMSEA $=0.042(90 \%$ CI, 0.028-0.055), $P=0.84$, SRMR $=0.036$ (Table 2). All factor loadings were significant and high except for the item "Get some exercise," which had a low but significant loading of 0.23 . The 2 dimensions or factors were positively correlated at 0.51 .

Scale Internal Coherence and Item Analysis.-We used the total sample to derive internal coherence estimates. When the a coefficient was computed, an adequate coefficient of .71 was obtained. However, a assumes that the items satisfy a unidimensional structure. Knowing that there are 2 dimensions represented in this scale, we used a reliability coefficient that takes multidimensionality into account - the global reliability index for multidimensional scales. ${ }^{54}$ This coefficient was better at $0.75 .{ }^{50}$ All the items had adequate discrimination, with an item-to-total corrected correlation greater than 0.30 .

\section{Symptom Perception Scale}

Dimensionality.-The 11-item Symptom Perception scale was hypothesized to have 2 dimensions. We hypothesized that most of the items in the scale would measure monitoring behaviors, but 2 items (How quickly did you recognize that you had symptoms? How quickly did you know that the symptom was due to HF?) were thought to measure symptom recognition. When a 2-factor model was tested, the model fit was adequate: $\chi^{2}(43, \mathrm{~N}=316)$ $=98.75, P<.001, \mathrm{CFI}=0.94, \mathrm{TLI}=0.92, \mathrm{RMSEA}=0.064$ (90\% CI, 0.047-0.081), $P=.08$, $\mathrm{SRMR}=0.045$. However, inspection of the modification indices suggested an estimation of 2 error covariances. One covariance was between "Keep a record of symptoms" and "Check for shortness of breath with activity." Because both items address symptoms, these 2 items were allowed to covary. Another covariance was between "Keep a record of symptoms" and "Ask your healthcare provider how you're doing." Because, presumably, the record of symptoms is kept to facilitate the discussion with the provider, the 2 items were allowed to covary.

When the model was respecified to include these error covariances, model fit was adequate: $\chi^{2}(41, \mathrm{~N}=316)=72.66, P<.01, \mathrm{CFI}=0.97, \mathrm{TLI}=0.95, \mathrm{RMSEA}=0.049(90 \% \mathrm{CI}, 0.03-$ $0.068), P=.50, \mathrm{SRMR}=0.041$. This final trimmed model was perfectly replicated on the second validation subsample: $\chi^{2}(41, \mathrm{~N}=315)=74.51 P<.01, \mathrm{CFI}=0.95, \mathrm{TLI}=0.93$, RMSEA $=0.051(90 \%$ CI, 0.032-0.069), $P=.44$, SRMR $=0.045$.

When we reran the CFA on the full sample of 631 subjects, the model fit was excellent: $\chi^{2}(41, \mathrm{~N}=631)=106.5, P<.001, \mathrm{CFI}=0.96, \mathrm{TLI}=0.94, \mathrm{RMSEA}=0.050(90 \% \mathrm{CI}$, $0.039-0.062$ ), $P=.46$, SRMR $=0.038$ (Table 2). All factor loadings were significant. The 2 dimensions were named monitoring behaviors and symptom recognition.

Scale Internal Coherence and Item Analysis.-When the internal coherence analysis was performed on the whole sample, the Cronbach a coefficient of the Symptom Perception scale was .81 . Knowing that $\mathrm{a}$ assumes a unidimensional structure and that 2 dimensions are represented in this scale, we used a reliability coefficient that takes multidimensionality into account—the global reliability index for multidimensional scales. ${ }^{54}$ This coefficient was better at $0.85 .{ }^{50}$ Regardless of the method used, the internal coherence of this scale was 
adequate. All items had adequate discrimination, with an item-to-total corrected correlation greater than 0.30 .

\section{Self-Care Management Scale}

Dimensionality.-The 8 items measuring self-care management were hypothesized to reflect 2 dimensions. One set of behaviors is recommended by providers: further limit the salt you eat that day, reduce your fluid intake, take a medicine, and call your healthcare provider for guidance. The second set of behaviors involves problem solving: ask a family member or friend for advice, try to figure out why you have symptoms, limit your activity until you feel better, and consider if the treatment you used made you feel better. Thus, we first specified a 2-factor CFA model. The goodness of fit indices of this model were very good: $\chi^{2}(19, \mathrm{~N}=316)=29, P=.06, \mathrm{CFI}=0.95, \mathrm{TLI}=0.93, \mathrm{RMSEA}=0.041(90 \% \mathrm{CI}$, $0.00-0.069), P=.67$, SRMR $=0.040$. This model had an excellent fit when the analysis was replicated on the second validation subsample: $\chi^{2}(19, \mathrm{~N}=315)=24.5, P=.18, \mathrm{CFI}=0.98$, $\mathrm{TLI}=0.96, \mathrm{RMSEA}=0.031(90 \% \mathrm{CI}, 0.00-0.061), P=.83, \mathrm{SRMR}=0.037$.

When we merged the 2 subsamples and reran the CFA on the full sample, the model had excellent fit indices: $\chi^{2}(19, \mathrm{~N}=631)=30.5, P=.05, \mathrm{CFI}=0.97$, TLI $=0.96, \mathrm{RMSEA}=$ 0.031 (90\% CI, 0.004-0.051), $P=.94$, SRMR $=0.029$ (Table 2). All factor loadings were significant, and factor correlation was 0.67 . The 2 factors were named recommended behaviors and problem-solving behaviors.

Scale Internal Coherence and Item Analysis.-We used the total sample to derive internal coherence estimates on the Self-Care Management scale. The a coefficient was not adequate (coefficient, .66), as expected, knowing that the scale has 2 dimensions. When we used the global reliability index for multidimensional scales, ${ }^{54}$ the coefficient was an adequate $0.70 .{ }^{50}$ All the items had adequate discrimination, with an item-to-total corrected correlation greater than 0.30 .

\section{Simultaneous Confirmatory Factor Analysis}

As a final step, we conducted a simultaneous CFA on the combined set of items using data from the total sample. Confirmatory factor analysis supported this more general model with the following fit indices: $\chi^{2}(360, \mathrm{~N}=631)=730, P<.001, \mathrm{CFI}=0.90, \mathrm{TLI}=0.89$, RMSEA $=0.04(90 \% \mathrm{CI}, 0.036-0.045), P=1.0$, SRMR $=0.046$. The factors underlying the scales emerged clearly in this combined analysis as can be seen in Table 2 (see factor loadings simultaneous analysis). Factor correlations ranged from 0.25 (symptom recognition with self-care maintenance dietary behaviors) to 0.76 (self-care monitoring behaviors with self-care maintenance consulting behaviors), with a mean (SD) of $0.498(0.16)$.

\section{Test-Retest Reliability}

When test-retest reliability was computed, correlations (corrected for the attenuation due to unreliability) were 0.89 for self-care maintenance, 0.70 for symptom perception, and 0.84 for self-care management. 


\section{Predictive Validity}

When self-care scores were analyzed in relation to HRQL, we found better general health in participants with higher self-care maintenance scores $(r=-0.19, P=.08)$ and higher symptom perception scores $(r=-0.31, P=.003)$. Mental health as measured by the SF-36 was better in participants with higher self-care maintenance scores $(r=-0.20, P=.06)$ and higher symptom perception scores $(r=-0.19, P=.08)$. The Physical Component Summary score, a measure of physical health, was better only in those with higher symptom perception scores $(r=-0.22, P=.04)$. Role limitations were not related to self-care. No relationship was found between self-care management and HRQL.

\section{DISCUSSION}

The aim of this study was to test the psychometric properties of the SCHFI v7.2 after it was revised to match the updated situation-specific theory of HF self-care. We supported factorial validity in the dimensions of self-care maintenance, symptom perception, and selfcare management in the SCHFI v7.2 and supported internal consistency and test-retest reliability. Predictive validity was demonstrated in relation to the SF-36. These results are extremely promising, and we are comfortable advocating use of the SCHFI v7.2 in research and clinical practice.

Because this revised version of the SCHFI was based on the updated situation-specific theory of HF self-care, ${ }^{7}$ we used CFA to test instrument validity. The process used in CFA was strong because we used half of the sample to develop the model according to the theory ${ }^{7}$ and previous work ${ }^{4,5,28,29}$ and the other half of the sample to validate the model. Then, we used the whole sample to obtain solid estimates for the final loadings. All of these steps demonstrated similar fit indices, attesting to the factorial validity of the instrument.

One item in the Self-care Maintenance scale, "get some exercise," performed poorly in model testing. This finding was not unexpected because authors of previous research have demonstrated that HF self-care behaviors are inconsistent ${ }^{22}$ and exercise is commonly low in patients with HF. ${ }^{55}$ Another item, "avoid cigarettes and tobacco smoke," was eliminated from the analysis. The item is not essential because it is not specific to HF, but we kept the item in the instrument and will continue to test the item and reconsider it in the future.

This was the first time we tested the newest SCHFI scale measuring symptom perception. In the previous version of the SCHFI v6.2, symptom monitoring was included in the Self-Care Maintenance scale and symptom recognition was captured in the Self-Care Management scale. However, authors of psychometric studies, ${ }^{4,5,28,29}$ conducted before updating the theory, demonstrated that these 2 items loaded on a single factor, providing evidence that symptom perception deserved more attention. In the SCHFI v7.2, 11 items address this new dimension of the theory. These items cover monitoring of daily weights and ankle swelling but also address new aspects of the concept. For example, looking for medication side effects, feeling tired, asking the provider how one is doing, and keeping a record of symptoms are all included in this scale. In this analysis, our hypothesis that symptom perception includes monitoring symptoms (eg, paying attention to changes in how one feels) and recognition of symptoms (eg, how quickly one recognizes HF symptoms) was 
confirmed in the analysis. Indeed, symptom monitoring implies that patients "listen" to their bodies, whereas recognition requires that patients engage in more active behaviors of symptom interpretation and attribution to the correct cause, which drives the treatment implemented during self-care management. ${ }^{31}$

The 8 items of the Self-Care Management scale, as hypothesized, fit the data well, reflecting 2 dimensions: recommended behaviors and problem-solving behaviors. These 2 dimensions reinforce previous studies in which it was shown that the management of HF symptoms includes performance of both recommended behaviors (eg, take a medicine) and problemsolving behaviors. ${ }^{56,57}$ Problem-solving behaviors reflect a realization that action is needed but there is some uncertainty about the situation (eg, Try to figure out why you have symptoms).

We also conducted a simultaneous CFA in which we tested the whole self-care model with the 3 scales, their dimensions, and the items belonging to each dimension. This analysis yielded fit indices that supported the whole model, providing evidence that the revised situation-specific theory of HF self-care, with 3 dimensions of self-care maintenance, symptom perception, and self-care management, fits the data well and is a faithful representation of how the self-care process works in patients with HF.

In previous work, we demonstrated that Cronbach a cannot be used to test the reliability of multidimensional scales. ${ }^{29}$ In this study, we further support this important point and advocate using the correct reliability estimate after assessing instrument dimensionality. In this analysis, Cronbach a coefficients were .71, .81, and .66 for the Self-Care Maintenance, Symptom Perception, and Self-Care Management scales, respectively. However, when we used the global reliability index for multidimensional scales, the reliability estimates reached $0.75,0.85$, and 0.70 , respectively. For future studies of the psychometric characteristics of the SCHFI, we strongly recommend first testing dimensionality and then choosing the best estimate of reliability based on dimensionality.

The reliability estimate of the Self-Care Management scale was only adequate, which may illustrate that self-care management behavior is inconsistent in patients with HF, as we found in a previous study. ${ }^{22}$ Test-retest reliability was adequate overall, demonstrating that the SCHFI v7.2 is stable in measuring self-care. The lowest estimate of stability was in symptom perception. This score may be evidence that symptoms changed over the 2-week testing period rather than instability of the scale. Symptoms are known to change rapidly in patients with HF, so presumably symptom monitoring behaviors change as well. ${ }^{58}$

Predictive validity of the SCHFI was supported with correlations between the SCHFI v7.2 scales and the SF-36. We found better physical and mental health in participants with higher self-care maintenance and/or symptom perception scores, which reinforces previous evidence that self-care can influence physical and mental health. ${ }^{22}$ The finding that self-care management was not related to HRQL was surprising, though, because others have found that improvements in self-care management are related to improvements in HRQL. ${ }^{59}$ This result may reflect the small sample size or the fact that data were collected while patients were hospitalized. 
Limitations of the study include the use of convenience sampling. Another limitation is that predictive validity and stability testing were performed in small subgroups of the sample, which may make our estimates unstable. Finally, the self-care behaviors measured reflect patients' perceptions of self-care and may not reflect actual self-care behaviors. A strength of the study was the large sample size collected at multiple sites.

Although this is the first psychometric test of the SCHFI v7.2, the instrument is based on theory and our previous work with the SCHFI, so we are comfortable advocating use of this new version of the SCHFI in research and clinical practice. In research, the SCHFI v7.2 is anticipated to better characterize the self-care process and predict outcomes better than the previous version. In clinical practice, results obtained using the SCHFI v7.2 can be used to tailor education to specific patient issues. Identifying where patients are struggling-in maintaining disease stability, in monitoring and "listening to their body," or in knowing what to do when symptoms get worse — can indicate what we should emphasize in patient teaching.

In conclusion, our psychometric analysis of the SCHFI v7.2 resulted in an improved instrument with characteristics that support factorial and predictive validity, internal consistency, and test-retest reliability. This is the first study testing the SCHFI v7.2, and more studies are needed. However, on the basis of our previous work on the SCHFI v6. $2^{4,5,28,29}$ and the theory supporting this new version of the SCHFI, ${ }^{7}$ we anticipate that the SCHFI v7.2 will be found to be valid and reliable in future studies. Translations of the SCHFI v7.2 into other languages are anticipated to be available on the website soon.

\section{REFERENCES}

1. Riegel B, Jaarsma T, Stromberg A. A middle-range theory of self-care of chronic illness. ANS Adv Nurs Sci. 2012;35(3): 194-204. [PubMed: 22739426]

2. Knafl GJ, Riegel B. What puts heart failure patients at risk for poor medication adherence? Patient Prefer Adherence. 2014;8: 1007-1018. [PubMed: 25114512]

3. Writing Committee M, Yancy CW, Jessup M, et al. 2013 ACCF/AHA guideline for the management of heart failure: a report of the American College of Cardiology Foundation/American Heart Association Task Force on practice guidelines. Circulation. 2013;128(16):e240-e327. [PubMed: 23741058]

4. Riegel B, Carlson B, Moser DK, Sebern M, Hicks FD, Roland V. Psychometric testing of the selfcare of heart failure index. J Card Fail. 2004;10(4):350-360. [PubMed: 15309704]

5. Riegel B, Lee CS, Dickson VV, Carlson B. An update on the self-care of heart failure index. J Cardiovasc Nurs. 2009;24(6): 485-497. [PubMed: 19786884]

6. Riegel B, Dickson VV. A situation-specific theory of heart failure self-care. J Cardiovasc Nurs. 2008;23(3):190-196. [PubMed: 18437059]

7. Riegel B, Dickson VV, Faulkner KM. The situation-specific theory of heart failure self-care: revised and updated. J Cardiovasc Nurs. 2016;31(3):226-235. [PubMed: 25774844]

8. Cameron J, Worrall-Carter L, Page K, Stewart S. Self-care behaviours and heart failure: does experience with symptoms really make a difference? Eur J Cardiovasc Nurs. 2010;9(2): 92-100. [PubMed: 20441991]

9. Dickson VV, Riegel B. Are we teaching what patients need to know? Building skills in heart failure self-care. Heart Lung. 2009;38(3):253-261. [PubMed: 19486796]

10. Karimi M, Clark AM. How do patients' values influence heart failure self-care decision-making? a mixed-methods systematic review. Int J Nurs Stud. 2016;59:89-104. [PubMed: 27222454] 
11. Bidwell JT, Vellone E, Lyons KS, et al. Determinants of heart failure self-care maintenance and management in patients and caregivers: a dyadic analysis. Res Nurs Health. 2015; 38(5):392-402. [PubMed: 26355702]

12. Chang LY, Wu SY, Chiang CE, Tsai PS. Depression and self-care maintenance in patients with heart failure: a moderated mediation model of self-care confidence and resilience. Eur $\mathbf{J}$ Cardiovasc Nurs. 2017;16(5):435-443. [PubMed: 28059552]

13. Cene CW, Haymore LB, Dolan-Soto D, et al. Self-care confidence mediates the relationship between perceived social support and self-care maintenance in adults with heart failure. J Card Fail. 2013;19(3):202-210. [PubMed: 23482082]

14. Dennison CR, McEntee ML, Samuel L, et al. Adequate health literacy is associated with higher heart failure knowledge and self-care confidence in hospitalized patients. J Cardiovasc Nurs. 2011;26(5):359-367. [PubMed: 21099698]

15. Vellone E, Fida R, D’Agostino F, et al. Self-care confidence may be the key: a cross-sectional study on the association between cognition and self-care behaviors in adults with heart failure. Int J Nurs Stud. 2015;52(11):1705-1713. [PubMed: 26169451]

16. Vellone E, Pancani L, Greco A, Steca P, Riegel B. Self-care confidence may be more important than cognition to influence self-care behaviors in adults with heart failure: testing a mediation model. Int J Nurs Stud. 2016;60:191-199. [PubMed: 27297380]

17. Fivecoat HC, Sayers SL, Riegel B. Social support predicts self-care confidence in patients with heart failure. Eur J Cardiovasc Nurs. 2018;1474515118762800.

18. Hammash MH, Crawford T, Shawler C, et al. Beyond social support: self-care confidence is key for adherence in patients with heart failure. Eur J Cardiovasc Nurs. 2017;16(7):632-637. [PubMed: 28443677]

19. Salyer J, Schubert CM, Chiaranai C. Supportive relationships, self-care confidence, and heart failure self-care. J Cardiovasc Nurs. 2012;27(5):384-393. [PubMed: 22048619]

20. Hooker SA, Schmiege SJ, Trivedi RB, Amoyal NR, Bekelman DB. Mutuality and heart failure self-care in patients and their informal caregivers. Eur J Cardiovasc Nurs. 2018;17(2):102-113. [PubMed: 28868917]

21. Dickson VV, McCarthy MM, Howe A, Schipper J, Katz SM. Sociocultural influences on heart failure self-care among an ethnic minority black population. J Cardiovasc Nurs. 2013; 28(2):111118. [PubMed: 22343210]

22. Vellone E, Fida R, Ghezzi V, et al. Patterns of self-care in adults with heart failure and their associations with sociodemographic and clinical characteristics, quality of life, and hospitalizations: a cluster analysis. J Cardiovasc Nurs. 2017; 32(2):180-189. [PubMed: 26938506]

23. Xu J, Gallo JJ, Wenzel J, et al. Heart failure rehospitalization and delayed decision making: the impact of self-care and depression. J Cardiovasc Nurs. 2018;33(1):30-39. [PubMed: 28574972]

24. Auld JP, Mudd JO, Gelow JM, Hiatt SO, Lee CS. Self-care moderates the relationship between symptoms and health-related quality of life in heart failure. J Cardiovasc Nurs. 2018;33(3):217224. [PubMed: 28930784]

25. Buck HG, Lee CS, Moser DK, et al. Relationship between self-care and health-related quality of life in older adults with moderate to advanced heart failure. J Cardiovasc Nurs. 2012; 27(1):8-15. [PubMed: 21558868]

26. Jonkman NH, Westland H, Groenwold RH, et al. Do self-management interventions work in patients with heart failure? An individual patient data meta-analysis. Circulation. 2016; 133(12):1189-1198. [PubMed: 26873943]

27. Lee CS, Bidwell JT, Paturzo M, et al. Patterns of self-care and clinical events in a cohort of adults with heart failure: 1 year follow-up. Heart Lung. 2018;47(1):40-46. [PubMed: 29054487]

28. Vellone E, Riegel B, Cocchieri A, et al. Psychometric testing of the Self-Care of Heart Failure Index Version 6.2. Res Nurs Health. 2013;36(5):500-511. [PubMed: 23832431]

29. Barbaranelli C, Lee CS, Vellone E, Riegel B. Dimensionality and reliability of the self-care of heart failure index scales: further evidence from confirmatory factor analysis. Res Nurs Health. 2014;37(6):524-537. [PubMed: 25324013]

30. Barbaranelli C, Lee CS, Vellone E, Riegel B. The problem with cronbach's alpha: comment on Sijtsma and van der Ark (2015). Nurs Res. 2015;64(2):140-145. [PubMed: 25738626] 
31. Vellone E, Riegel B, D'Agostino F, et al. Structural equation model testing the situation-specific theory of heart failure self-care. J Adv Nurs. 2013;69(11):2481-2492. [PubMed: 23521633]

32. Hassanpour MS, Simmons WK, Feinstein JS, et al. The insular cortex dynamically maps changes in cardiorespiratory intero-ception. Neuropsychopharmacology. 2018;43(2):426-434. [PubMed: 28726799]

33. Woo MA, Yadav SK, Macey PM, Fonarow GC, Harper RM, Kumar R. Brain metabolites in autonomic regulatory insular sites in heart failure. J Neurol Sci. 2014;346(1-2):271-275. [PubMed: 25248953]

34. Norman GR, Sloan JA, Wyrwich KW. Interpretation of changes in health-related quality of life: the remarkable universality of half a standard deviation. Med Care. 2003;41(5): 582-592. [PubMed: 12719681]

35. Muthén LK, Muthén BO. Mplus User's Guide. 8th ed Los Angeles, CA: Muthén \& Muthén; 19982017.

36. Comrey AL, Lee HB. A First Course in Factor Analysis. 2nd ed Hillsdale, NJ: Erlbaum; 1992.

37. Tabachnick BG, Fidell LS. Using Multivariate Statistics. 5th ed Boston, MA: Pearson Education, Inc; 2007.

38. Byrne BM. Structural Equation Modeling With EQS: Basic Concepts, Applications, and Programming. 2nd ed Mahwah, NJ: Lawrence Erlbaum Associates, Inc; 2006.

39. Meade AW, Johnson EC, Braddy PW. Power and sensitivity of alternative fit indices in tests of measurement invariance. J Appl Psychol. 2008;93(3):568. [PubMed: 18457487]

40. Vandenberg RJ, Lance CE. A review and synthesis of the measurement invariance literature: suggestions, practices, and recommendations for organizational research. Org Res Method. 2000;3(1):4-70.

41. Bentler PM. Comparative fit indexes in structural models. Psychol Bull. 1990;107:238-246. [PubMed: 2320703]

42. Hu L, Bentler PM. Cutoff criteria for fit indexes in covariance structure analysis: conventional criteria versus new alternatives. Struct Equat Model. 1999;6:1-55.

43. Browne MW, Cudek R. Alternative ways of assessing model fit In: Bollen KA, Long JS, eds. Testing Structural Equation Models. Newbury Park, CA: Sage; 1993:136-162.

44. Anderson JC, Gerbing DW. Structural equation modeling in practice: a review and recommended two-step approach. Psychol Bull. 1988;103:411-423.

45. Hoyle RH, Panter AT. Writing about structural equation models In: Hoyle RH, ed. Structural Equation Modeling: Concepts, Issues, and Applications. Thousand Oaks, CA: Sage Publications; 1995.

46. Fornell C, Larcker D. Evaluating structural equation models with unobservable variable and measurement error. J Market Res. 1981;18:39-50.

47. McDonald RP. Test Theory: A Unified Treatment. 1st ed Mahwah, NJ: Lawrence Erlbaum Associates; 1999.

48. Bagozzi RP, Yi Y. Specification, evaluation, and interpretation of structural equation models. J Acad Market Sci. 2012;40(1):8-34.

49. Crocker L, Algina J. Introduction to Classical and Modern Test Theory. Orlando, FL: Holt, Rinehart and Winston, Inc; 1986.

50. Nunnally J, Bernstein IH. Psychometric Theory. New York, NY: McGraw Hill, Inc; 1994.

51. Ware JE Jr, Kosinski M, Bjorner JB, Turner-Bowker DM, Gandek B, Maruish ME. User's Manual for the SF-36v2 Health Survey. 2nd ed Lincoln, RI: QualityMetric Incorporated; 2007.

52. Charlson M, Pompei P, Ales K, MacKenzie CR. A new method of classifying prognostic comorbidity in longitudinal studies: development and validation. J Chronic Dis. 1987;40: 373-383. [PubMed: 3558716]

53. Lin CY, Pakpour AH, Brostrom A, et al. Psychometric properties of the 9-item European Heart Failure Self-care Behavior Scale using confirmatory factor analysis and Rasch analysis among Iranian patients. J Cardiovasc Nurs. 2018;33(3): 281-288. [PubMed: 28858887]

54. Raykov T. Scale Construction and Development Using Structural Equation Modeling. New York, NY: The Guilford Press; 2013. 
55. Jaarsma T, Stromberg A, Ben Gal T, et al. Comparison of self-care behaviors of heart failure patients in 15 countries worldwide. Patient Educ Couns. 2013;92(1):114-120. [PubMed: 23579040]

56. Graven LJ, Gordon G, Keltner JG, Abbott L, Bahorski J. Efficacy of a social support and problemsolving intervention on heart failure self-care: a pilot study. Patient Educ Couns. 2018;101(2):266275. [PubMed: 28951026]

57. Riegel B, Dickson VV, Garcia LE, Masterson Creber R, Streur M. Mechanisms of change in selfcare in adults with heart failure receiving a tailored, motivational interviewing intervention. Patient Educ Couns. 2017;100(2):283-288. [PubMed: 27599712]

58. Jurgens CY, Hoke L, Byrnes J, Riegel B. Why do elders delay responding to heart failure symptoms? Nurs Res. 2009;58(4): 274-282. [PubMed: 19609179]

59. Lee CS, Mudd JO, Hiatt SO, Gelow JM, Chien C, Riegel B. Trajectories of heart failure self-care management and changes in quality of life. Eur J Cardiovasc Nurs. 2015;14(6):486-494.

[PubMed: 24982435] 


\section{What's New and Important}

- $\quad$ The SCHFI has been revised to match the updated situation-specific theory of HF self-care.

- $\quad$ The revised SCHFI now has 3 scales measuring the 3 concepts of the theory: Self-Care Maintenance, Symptom Perception, and Self-Care Management.

- $\quad$ The revised SCHFI is valid, reliable, and freely available to users on the website: www.self-care-measures.com. 
TABLE 1

Sociodemographic and Clinical Characteristics of the Sample $(\mathrm{N}=631)$

\begin{tabular}{|c|c|}
\hline & Mean \pm SD or $n(\%)$ \\
\hline Age $(N=626), y$ & $64.6 \pm 14.3$ \\
\hline \multicolumn{2}{|l|}{ Gender $(N=628)$} \\
\hline Male & $396(63.1)$ \\
\hline Female & $232(36.9)$ \\
\hline \multicolumn{2}{|l|}{ Race $(\mathrm{N}=604)$} \\
\hline Black/African American & $131(21.7)$ \\
\hline White/Caucasian & $432(71.5)$ \\
\hline Asian & $5(0.8)$ \\
\hline Other (eg, mixed race) & $36(6)$ \\
\hline \multicolumn{2}{|l|}{ Ethnicity $(\mathrm{N}=455)$} \\
\hline Hispanic & $36(7.9)$ \\
\hline Non-Hispanic & $419(92.1)$ \\
\hline \multicolumn{2}{|l|}{ Highest education $(\mathrm{N}=608)$} \\
\hline Less than high school graduate & $61(10)$ \\
\hline High school graduate, vocational, or trade school & $212(34.9)$ \\
\hline Some college or associate degree & $214(35.2)$ \\
\hline Bachelor's degree or higher & $121(19.9)$ \\
\hline \multicolumn{2}{|l|}{ Employment $(\mathrm{N}=608)$} \\
\hline Employed & $131(21.6)$ \\
\hline Unemployed or retired & $477(78.5)$ \\
\hline \multicolumn{2}{|l|}{ Marital status $(\mathrm{N}=631)$} \\
\hline Single, never married & $112(17.8)$ \\
\hline Married or partnered & $346(54.8)$ \\
\hline Divorced, separated, or widowed & $173(27.4)$ \\
\hline \multicolumn{2}{|l|}{ Self-reported income $(\mathrm{N}=613)$} \\
\hline More than enough to make ends meet & $206(33.6)$ \\
\hline Enough to make ends meet & $279(45.5)$ \\
\hline Not have enough to make ends meet & $128(20.9)$ \\
\hline HF duration in months $(\mathrm{N}=514)$ & $126.7 \pm 130.4$ \\
\hline \multicolumn{2}{|c|}{ Categorized Charlson Comorbidity Index $(\mathrm{CCI})$ score $(\mathrm{N}=629)$} \\
\hline Low level (CCI 1-2) & $337(53.4)$ \\
\hline Moderate level (CCI 3-4) & $188(29.8)$ \\
\hline High level $(\mathrm{CCI}>5)$ & $106(16.8)$ \\
\hline \multicolumn{2}{|l|}{ Common comorbid conditions ${ }^{a}$} \\
\hline Hypertension & $406(64.3)$ \\
\hline Diabetes & $253(40.1)$ \\
\hline Arthritis & $247(39.2)$ \\
\hline Dysrhythmia $^{b}$ & $135(31.2)$ \\
\hline Other heart condition & $190(30.2)$ \\
\hline
\end{tabular}




\begin{tabular}{|c|c|}
\hline & Mean \pm SD or $n(\%)$ \\
\hline Pulmonary disease & $183(29.1)$ \\
\hline Renal disease & $142(22.6)$ \\
\hline Solid tumor cancer & $83(13.2)$ \\
\hline Neurological disorders & $78(12.4)$ \\
\hline Mental health issue ${ }^{b}$ & $46(10.6)$ \\
\hline Anemia $^{b}$ & $43(9.9)$ \\
\hline Peripheral vascular disease ${ }^{b}$ & $29(6.7)$ \\
\hline Gastrointestinal disease $^{b}$ & $26(6)$ \\
\hline Liver disease & $32(5.1)$ \\
\hline Blood cancer $b$ & $9(2.1)$ \\
\hline Other diseases $b$ & $57(13.2)$ \\
\hline
\end{tabular}

Abbreviation: HF, heart failure.

aEach disease was treated individually, so the percentage under "common comorbidity conditions" is not 100 .

${ }^{b}$ Only some of the patients (433/631) were asked about these specific comorbid conditions. 


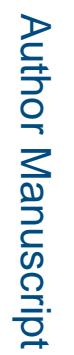

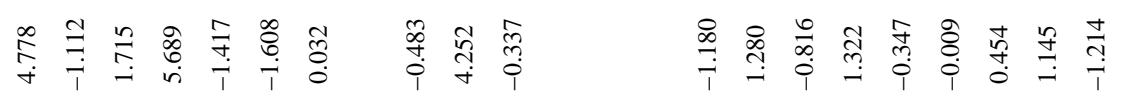

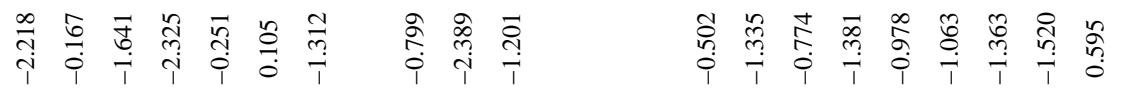

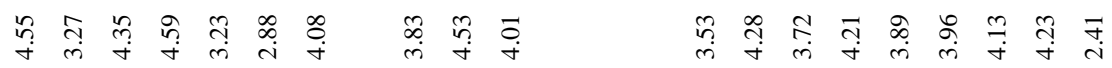

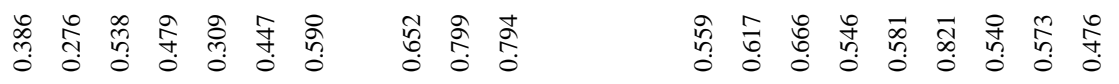

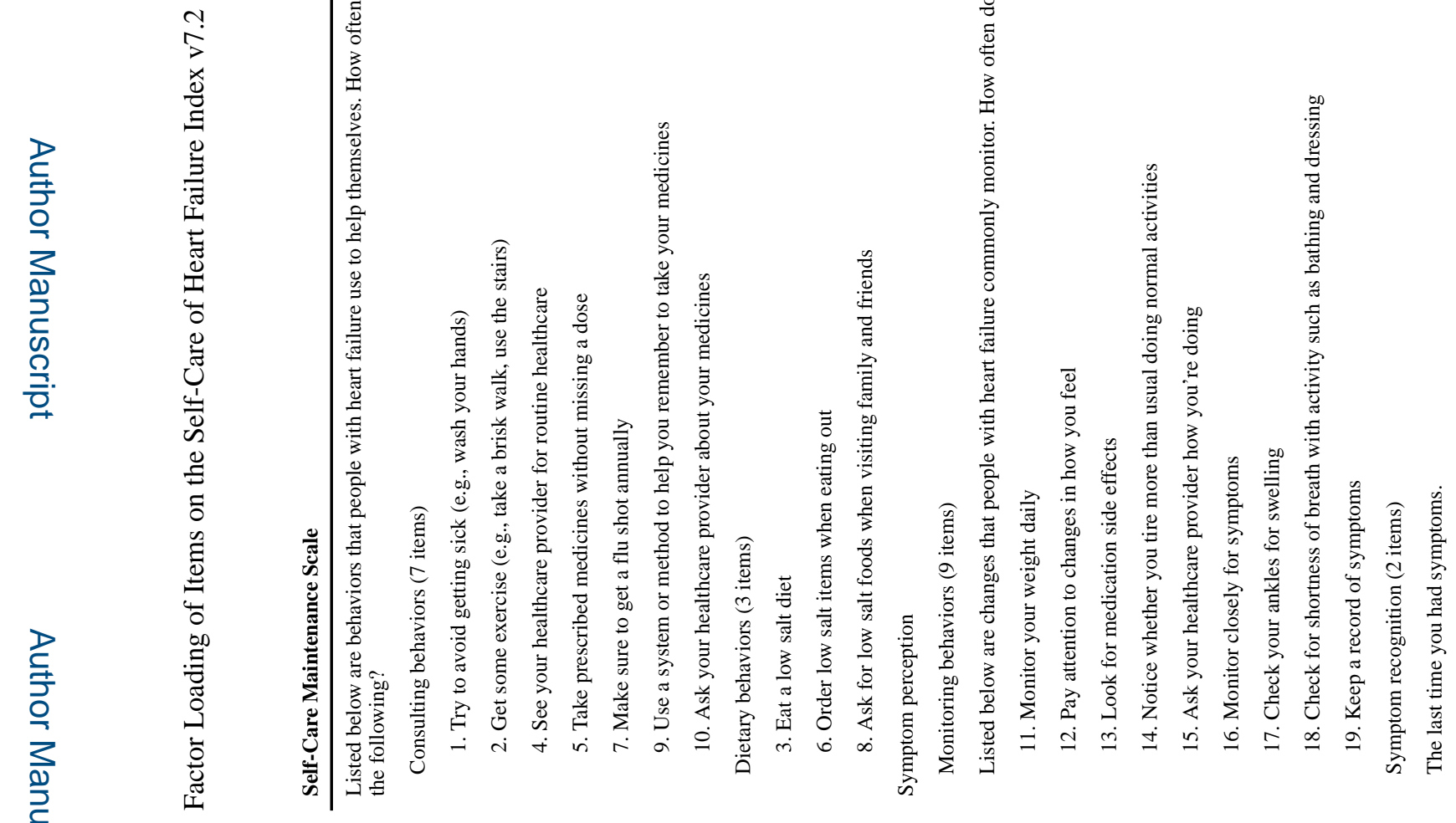


Riegel et al.

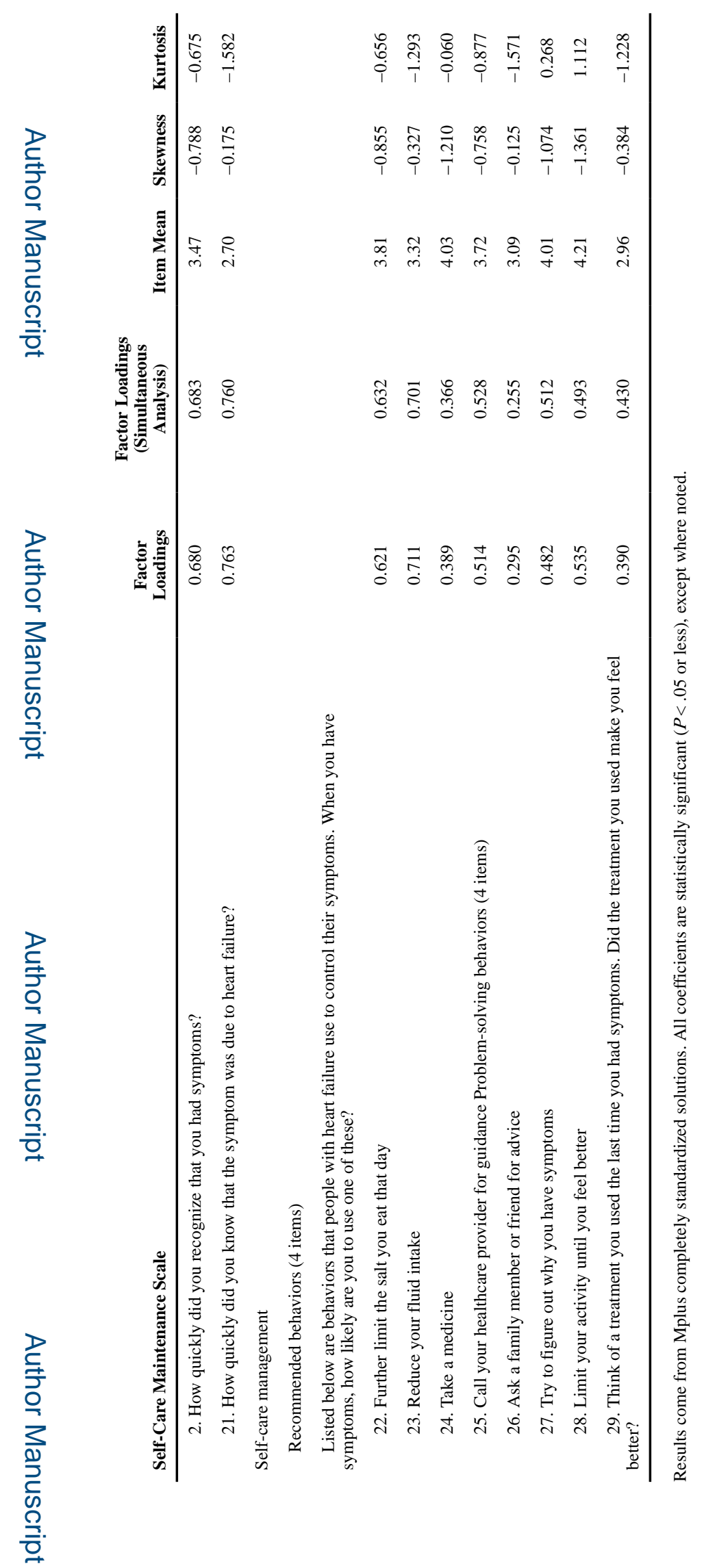

J Cardiovasc Nurs. Author manuscript; available in PMC 2020 April 23. 